\title{
DisPaRIDADES INTERNACIONAIS E MERCADO INTERNO: UMA COMPARAÇÃO ENTRE AS análises de Celso Furtado e as PRESCRIÇÕES DOS RDHs/PNUD/ONU
}

\author{
Fábio Akira SHISHITO* \\ Maria José de REZENDE*
}

\begin{abstract}
RESUMO: As análises de Celso Furtado demonstraram quais eram as travas que impedem, em cada contexto sócio-histórico, o desenvolvimento social e humano na América Latina em geral, e no Brasil, em particular. Essa investigação adota, então, uma perspectiva metodológica qualitativa realizada por meio de uma análise bibliográfica e documental, cujo objetivo é desvendar os sentidos e significados políticos das abordagens prospectivas de Celso Furtado e dos elaboradores dos Relatórios do Desenvolvimento Humano (RDHs) analisadas neste artigo. Cabe destacar que a diferença central entre essas duas formas de tratar o desenvolvimento está no modo como cada uma delas lida com o processo sócio-histórico no concernente aos bloqueios que se interpõem na construção de um devir valorizador das melhorias humanas.
\end{abstract}

PALAVRAS-CHAVE: Desenvolvimento social e humano. Devir. Abordagens prospectivas.

\section{Introdução}

Os diagnósticos e as prescrições presentes nos Relatórios do Desenvolvimento Humano (RDHs) encomendados, encampados e divulgados pelo Programa das

USP - Universidade de São Paulo. Faculdade de Filosofia Letras e Ciências Humanas. São Paulo SP - Brasil. 05508-080 - akira.shishito@hotmail.com. https://orcid.org/0000-0002-0821-2281.

* UEL - Universidade Estadual de Londrina. Programa de Pós-Graduação em Sociologia. Londrina PR - Brasil. 86057-970 - mjderezende@gmail.com. https://orcid.org/0000-0002-3426-910X. 
Nações Unidas para o Desenvolvimento (PNUD), desde 1990, podem ser lidos e interpretados à luz dos debates propostos pelos pensadores sociais brasileiros e latino-americanos que, durante décadas, estiveram voltados para os problemas relacionados às dificuldades e (im)possibilidades de converter o crescimento econômico, o aumento da produtividade, os avanços técnicos e o aperfeiçoamento das instituições estatais e da administração pública em melhorias sociais e coletivas.

Na América Latina, entre as décadas de 1950 e 1990, há uma vasta produção a respeito do desenvolvimento. Celso Furtado (1920-2004) se destacou nesse debate como um dos principais intelectuais do século XX. É inteiramente cabível estabelecer comparações entre os diagnósticos e prescrições tecidos ao longo de suas obras e diversas outras perspectivas e proposições acerca do desenvolvimento.

No âmbito deste artigo, pretende-se fazer uma interpretação de alguns RDHs (os de 1992, 1994, 1996) ${ }^{1}$ - tendo-se em vista que é impossível eleger todos os documentos publicados ao longo de 27 anos, ou seja, anualmente, desde 1990 - à luz das discussões feitas por Celso Furtado entre 1990 e 2004. Considera-se que a simultaneidade entre os últimos escritos de Furtado e a redação e divulgação dos primeiros RDHs possibilita compará-los, já que eles têm como referências, em suas abordagens prospectivas, os mesmos acontecimentos históricos, os mesmos processos sociais e as mesmas conjunturas.

Deve-se atentar, porém, para as diferenças existentes entre as abordagens prospectivas que possuem caráter genérico e abrangente demais - como é o caso dos RDHs, cuja finalidade é gerar diagnósticos e prognósticos condizentes com os contextos mais diversos - e as abordagens prospectivas, como as de Celso Furtado, embasadas nas singularidades econômicas, sociais e políticas de um país e/ou de uma região.

Não há dúvida de que as abordagens prospectivas generalistas, ou não, lidam, direta ou indiretamente, com a contraposição e/ou com a relação entre desenvolvimento e as múltiplas temáticas com as quais o desenvolvimento se conecta, e que foram significativamente exploradas ao longo da segunda metade do século $\mathrm{XX}^{2}$ quais sejam: crescimento econômico, democracia, bem-estar social, mercado, capitalismo, dependência externa, urbanização, empregabilidade, entre outros.

Norteará este estudo o seguinte problema: Como as análises de Celso Furtado sobre disparidades internacionais e mercado interno, realizadas nas décadas de 1990, desafiam as prescrições, contidas nos RDHs, de ações e de políticas favoráveis ao desenvolvimento humano? Tentar-se-á responder a esse questionamento por meio

\footnotetext{
1 Os relatórios (PNUD/RDH, 1998; 1999; 2001 e 2003) fornecem também dados relevantes para as temáticas discutidas neste artigo.

2 Alguns estudos, entre muitos outros, podem ser tomados como impulsionadores desses debates (AGARWALA e SINGH, 2010; WOORTMANN, 1991; GOLDTHORPE, 1977; HIRSCHMAN, 1986; PINTO, 1976; TOLIPAN e TINELLI, 1975; STREETEN, 1982; PREBISCH, 1964; 1986; 1987; CEPAL, 1963; FURTADO, 1961; 1964; 1974; 1978; 1981).
} 


\section{Disparidades internacionais e mercado interno: uma comparaçáo entre as análises de Celso Furtado e as prescriçôes dos RDHs/PNUD/ONU}

de uma pesquisa documental que analisará os RDHs de 1992, 1994 e 1996 e os escritos de Celso Furtado das décadas de 1990 e 2000. Demonstrar-se-á a natureza distinta dessas duas abordagens prospectivas (a contida nos RDHs e a contida nos escritos de Furtado).

Quando abraçam a perspectiva do desenvolvimento humano, os elaboradores dos RDHs o fazem seguindo algumas trilhas abertas por dois cientistas - Amartya Sen $(2005 ; 2011)$ e Mahbud Ul Haq (1995) - que, ao longo das últimas décadas do século XX, também estiveram voltados para a temática do desenvolvimento nos países periféricos. Sen, junto com U1 Haq, foi um dos idealizadores dos Índices do Desenvolvimento Humano (IDHs) e RDHs. A noção de desenvolvimento humano, que, conforme afirma Fukuda Parr (2002), serve como baliza para os diagnósticos e prescrições contidos nos relatórios, tem inspiração nos escritos de Amartya Sen, o qual ressalta a importância de associar expansão das capacidades e melhoria da qualidade de vida. Diz ele

[a] expansão dos serviços de saúde, educação, seguridade social etc. contribui diretamente para a qualidade da vida e seu florescimento. Há evidências até de que, mesmo com renda relativamente baixa, um país que garante serviços de saúde e educação a todos pode efetivamente obter resultados notáveis da duração e qualidade da vida de toda a população. [...] As recompensas do desenvolvimento humano [...] vão muito além da melhora direta da qualidade de vida, e incluem também sua influência sobre as habilidades produtivas das pessoas e, portanto, sobre o crescimento econômico em uma base amplamente compartilhada. Saber ler e fazer contas ajuda as massas a participar do processo de expansão econômica (SEN, 2010, p.191).

Não será possível, no âmbito deste artigo, traçar comparações entre as abordagens de Furtado e as de U1 Haq e Sen. Ainda que todos eles estivessem, ao longo da segunda metade do século XX, ocupados com a construção de diferentes propostas de desenvolvimento para os países periféricos, não serão tratadas aqui as semelhanças e dessemelhanças entre suas perspectivas teóricas e políticas. Não será possível, então, comparar a abordagem de Furtado e a de Sen, uma vez que esta é muito mais complexa e elaborada do que o conjunto de prescrições acerca do desenvolvimento humano que aparece nos RDHs. Considera-se possível comparar diretamente as abordagens prospectivas de Celso Furtado e as contidas nos RDHs em razão do modo singularizado pelo qual a noção de desenvolvimento humano foi assumindo no interior desses documentos. 


\section{A centralidade da dimensão política em Celso Furtado}

Um ponto de partida possível para pensar a noção de desenvolvimento em Furtado e entender como as suas contribuições teóricas podem colaborar para os desvendamentos dos entraves ao desenvolvimento humano no Brasil é a centralidade da dimensão política presente nos conflitos pela definição do devir em sociedade.

Partir dessa perspectiva significa levar em conta que a noção de desenvolvimento em Furtado ancora-se, primeiramente, num modo particular de compreensão do fenômeno econômico. Em $O$ mito do desenvolvimento econômico ele assevera: “(...) toda decisão econômica é parte de um conjunto de decisões com importantes projeções no tempo. Essas decisões encontram sua coerência última num projeto que introduz um sentido unificador na ação do agente ${ }^{3 "}$ (FURTADO, 1974, p. 112 itálico no original).

Ele não está pensando, nesse caso, exclusivamente nas grandes decisões econômicas no âmbito do Estado ou do mercado, mas sim tentando equacionar teoricamente um tipo de ação social e que, como tal, não responde a critérios de absoluta previsibilidade. Sua perspectiva dá, em seus escritos, indicação acerca da relevância da dimensão política. São muitos os conflitos a respeito da definição do devir em sociedade ou, seja, sobre a definição dos projetos que darão sentido às ações sociais. Desse modo, parece claro que o desenvolvimento não somente diz respeito a um problema de crescimento econômico e distribuição de rendimentos, mas consiste, também, no modo como se organiza, ou se distribui, o poder. Essa forma de entendimento da ideia de desenvolvimento em Furtado aparece, por exemplo, na definição de Carlos Brandão:

O conceito de desenvolvimento proposto pela obra furtadiana se baseia no estudo da natureza do processo de exercitar opções alternativas frente a uma temporalidade construída mais larga (e não-imediatista), apta a escolhas autônomas, apresentando trajetórias abertas, sujeitas a decisões estratégicas, em ambiente de incerteza, e de diferenciação de poder (de comando sobre o destino) de agentes desigualmente constituídos. (BRANDÃO, 2012, p. 2-3).

Desse ponto de vista, com seu empreendimento, Celso Furtado caminhou no sentido de propor o alargamento das capacidades e a viabilização da participação societal na decisão sobre seu destino, considerando as desigualdades estruturais

\footnotetext{
3 Sobre a importância da dimensão política em Celso Furtado, ver: (CÊPEDA, 2005; 2012)

4 "Parte de uma perspectiva [de] que desenvolvimento, necessariamente envolve tempo e espaço nas decisões de como alocar (intertemporalmente, interespacialmente, intersetorialmente etc.) ativos, recursos, capacitações, produtivamente ou não, ou seja, envolve a questão da destinação do excedente social" (BRANDÃO, 2012, p.3).
} 


\section{Disparidades internacionais e mercado interno: uma comparaçáo entre as análises de Celso Furtado e as prescriçôes dos RDHs/PNUD/ONU}

como ponto de partida e abordando o desenvolvimento como ideia que se projeta no tempo e no espaço.

O ponto de partida da reflexão sobre o desenvolvimento é a apreensão da realidade social; mais precisamente, a identificação das entidades que assumem as novas formas. Essa realidade é apreendida, por um lado, como algo estruturado e, por outro, desdobrando-se no tempo, vale dizer, como um processo. (FURTADO, 2000 , p. 41 , grifos do original).

Essa é uma das contribuições relevantes, prisma a partir do qual se aborda o desenvolvimento, considerando-se, sobretudo, que as possibilidades estão sempre limitadas por entraves fortemente enraizados. Tais entraves inscrevemse nas formas particulares de inserção, de muitos países periféricos, na economia internacional, vale dizer, como exportadores de produtos primários e importadores de produtos manufaturados. "Convenci-me então de que o subdesenvolvimento era a resultante de um processo de dependência e que, para compreendê-lo, era necessário estudar a estrutura do sistema global: identificar as invariâncias no quadro de sua história" (FURTADO, 2002, p. 73). Isso significava, de um lado, compreender no interior das relações estabelecidas entre países centrais e periféricos as consequências econômicas da situação de dependência e, de outro, os impactos sociais e culturais resultantes do processamento histórico do subdesenvolvimento. A busca pelas invariâncias nesses aspectos facultou-lhe a construção da noção central de parâmetros estruturais, entre os quais se destaca o problema das desigualdades (de renda, de terra, educacional, de acesso à saúde etc.).

Por essa razão, como realidade projetada no futuro, Furtado concebia o desenvolvimento como eliminação das chamadas heterogeneidades sociais, isto é, a desigual distribuição dos excedentes produzidos socialmente. Essa tarefa, segundo ele, passava por uma atuação indispensável do Estado, assim como por uma participação efetiva da sociedade, concepção que o levou a refletir, em vários de seus textos, sobre como equacionar as travas institucionais que obstavam a implantação de projetos de desenvolvimento dessa natureza e sobre como elaborar, na sociedade, um projeto efetivamente coletivo de Nação. "Trata-se de saber [diz ele] se temos um futuro como nação que [se soma] na construção do devir humano. Ou se prevalecerão as forças que se empenham em interromper o nosso processo histórico de formação de um Estado-nação" (FURTADO, 1992, p. 35).

A relevância do Estado atravessa toda a obra de Furtado. Se o desenvolvimento é entendido como possibilidade de reorientação dos excedentes que se produzem numa sociedade, a realização institucional dessa ideia ganha o contorno de políticas públicas. Furtado tinha plena ciência de que políticas com tais objetivos só seriam possíveis em espaços de conflito e construção coletiva de ideias no interior do 
Estado. Isso quer dizer, ao mesmo tempo, duas coisas: 1) é necessária a existência de uma vontade coletiva como força mediadora dos centros de decisão e 2) não é crível a ideia de que as necessidades humanas possam ser resolvidas pelas forças "naturais" do mercado. A "miséria absoluta somente foi abolida ali onde uma vontade política se propôs a esse objetivo" (FURTADO, 2012 [1986], p. 63-64).

Um terceiro aspecto, que se desdobra do debate anteriormente proposto, é a relevância que assume a questão cultural como entrave ao processo de desenvolvimento, sobretudo quando se ressalta a importância da vontade coletiva. Quando pensa a superação do subdesenvolvimento, Furtado pensa sobrepujar três níveis de necessidades: as elementares, ligadas à sobrevivência, as ligadas ao convívio, como a comunicação e a segurança e, por fim, aquelas em que o exercício da liberdade é fundamental, às quais podem ser designadas - talvez imprecisamente - de necessidades políticas. "O homem realiza suas potencialidades questionando-se a si mesmo, como sujeito ativo que busca construir seu próprio destino" (FURTADO, 2012 [1986], p. 64).

Desse quadro sumário de proposições teóricas desdobra-se, então, uma visão prospectiva exigente. Entre as condições urgentes que devem ser cumpridas, pelos países periféricos, para enfrentar o subdesenvolvimento, as mais relevantes, segundo Furtado, são: (i) um grau de autonomia decisório que impeça a drenagem do potencial econômico para o exterior; (ii) estruturas de poder capazes de frear a tendência à modernização dos padrões de consumo e de reverter o potencial de investimento para o fator humano; (iii) descentralização do poder decisório empresarial para gerar um sistema de incentivos que potencialize o sistema produtivo; (iv) estruturas sociais que, operando com maior frequência a partir de uma racionalidade substantiva, consigam oferecer resistência social e política nos ambientes de alta concentração de poder (FURTADO, 1995). Todas as condições apontadas pelo autor são reveladoras da profundidade e da complexidade da temática, mas nos apresentam a possibilidade de examinar as diferenças de abordagem e os desafios colocados pelo pensador brasileiro.

\section{As disparidades internacionais e o mercado interno: as prescrições postas nos RDHs da década de 1990 e os desafios suscitados pelas discussões de Celso Furtado}

A disposição de testar a abordagem do desenvolvimento humano, posta nos RDHs, à luz de contextos específicos, exige um constante diálogo com pensadores que se preocuparam com as singularidades histórico-processuais de alguns países e regiões. Neste caso, os escritos de Celso Furtado tornam-se férteis para desvendar os 


\section{Disparidades internacionais e mercado interno: uma comparação entre as análises de Celso Furtado e as prescriçóes dos RDHs/PNUD/ONU}

diagnósticos e as prescrições voltadas para a América Latina. No caso das discussões presentes nos RDHs da década de 1990 acerca das disparidades internacionais e de suas consequências para os países pobres, notam-se tentativas, por parte dos elaboradores dos relatórios, de pautar ações e procedimentos que parecem exequíveis porque se desviam dos jogos complexos, para usar uma expressão de Norbert Elias (1998; 1999; 1999a), em múltiplos níveis que foram desencadeados pelas "mudanças conjunturais e mesmo estruturais da economia internacional" (FURTADO, 1992a, p. 5).

Tais desvios podem ser observados em várias ocasiões e em vários documentos. O RDH de 1994, ao discutir a necessidade de enfrentar temas espinhosos como a diminuição das despesas militares, a redefinição das condições referentes ao pagamento dos compromissos relacionados com a dívida externa dos países pobres, a expansão tecnológica e o aprofundamento das desigualdades entre nações no mercado internacional, passava a fazer prescrições dissociadas das dificuldades sociais, econômicas e políticas aventadas no decorrer do próprio documento. Em seus diagnósticos, os formuladores do RDH de 1996 destacaram as crescentes disparidades entre nações e a acentuada polarização econômica que estava tomando contornos cada vez maiores. Por isso, a "continuar las tendencias actuales, las disparidades económicas entre países industrializados y en desarrollo ya no serán sólo inequitativas y pasarán a ser inhumanas" (PNUD/RDH, 1996, p. III).

Nota-se, então, algo que deve ser considerado um nó nos relatórios. Os diagnósticos são feitos com base nos jogos políticos e de poderes ultracomplexos em múltiplos níveis (ELIAS, 1999a), mas as prescrições parecem ancoradas em jogos de interesses muito menos complexos. Pode-se dizer que os diagnósticos são produzidos com um número maior de elementos realistas e que as prescrições estão mais assentadas em elementos fantasiosos, por exemplo, na possibilidade de construir consensos sobre temas espinhosos, tais como despesas militares, ajudas internacionais, cooperações entre países, perdão de dívidas externas, negociações favoráveis aos países pobres, entre outras sugestões. Além disso, percebe-se certo desinteresse, por parte dos formuladores das prescrições, pela dimensão da construção histórica das instituições, dos países considerados desenvolvidos, que lhes servem de exemplo. No RDH de 1994 afirma-se:

(...) por ese motivo, un nuevo método de cooperación para el desarrollo tendrá que ser más incluyente y más coherente. La inversión extranjera directa, el comercio internacional, las corrientes de capital (...) son todos factores que tendrán que contribuir al desarrollo humano en el Sur y a promover una mayor equidad a escala mundial. (PNUD/RDH de 1994, p. 73). 
Ha-Joon Chang (2004), a esse respeito, mostra precisamente que instituições, como as leis antitruste, para regulamentar o comércio internacional, nem sempre fizeram parte da história econômica dos países centrais, razão pela qual comparar os diagnósticos e os prognósticos feitos nos RDHs e os presentes nas discussões de Celso Furtado (1998; 1998a, 1999; 2002; 2002a; 2003; 2003a) é útil não só para entender ambas as posturas prospectivas relacionadas às complexas disparidades de poder, no âmbito nacional e internacional, e ao, cada vez maior estreitamento das saídas para os países do Hemisfério Sul, mas também para comparar o grau de realismo e de fantasias que certamente existe nessas duas abordagens. Não se pode imaginar que as perspectivas científicas são destituídas de elementos fantasiosos. O próprio Celso Furtado (1974; 1997; 1997a; 1997b; 1999a; 2004; 2004a; 2004b) discutiu isso em vários momentos de sua trajetória acadêmica, estando ele e Norbert Elias (1999b) entre os cientistas sociais que se destacaram na discussão sobre o enlaçamento dos elementos realistas e fantasiosos. Norbert Elias (1999b) diz:

(...) é característica do nosso tempo a coexistência de uma compreensão factual altamente realista, no que [diz respeito] a aspectos físicos e técnicos, e de soluções fantasiosas dadas aos problemas sociais, problemas esses que atualmente não queremos ou ainda não conseguimos explicar e ultrapassar com mais eficiência. (ELIAS, 1999b, p.28).

Furtado (1992a, p.5), na década de 1990, advoga a necessidade de entender, por que, interna e externamente, foram abandonadas e/ou descartadas as "estratégias de construção do mercado interno como motor de crescimento". É primordial, todavia, compreender, se é possível também, que esta proposta seja retomada no final do século XX e limiar do XXI. Essas duas questões podem ser examinadas à luz da proposta de Norbert Elias (1999b) assentada na distinção entre os elementos realistas e fantasiosos. Comparando-se as duas abordagens prospectivas acerca das possibilidades de enfrentar as disparidades internacionais na área social, econômica e política, notam-se feixes maiores de elementos fantasiosos nas prescrições construídas pelos formuladores dos RDHs e feixes maiores de elementos realistas nas soluções aventadas como possíveis, ou não, nos escritos e entrevistas de Celso Furtado.

O RDH de 1996, intitulado ¿Crecimiento económico para propiciar el desarrollo humano? procura diagnosticar as causas e consequências de um crescimento desconectado do desenvolvimento humano. Os seus formuladores buscam cercar-se de diversos elementos embasados nas experiências reais postas em prática na segunda metade do século XX para convencer governantes, lideranças políticas, organizações internacionais e da sociedade civil, de modo geral, que esse modelo de expansão econômica tinha sido inócuo para a grande maioria 


\section{Disparidades internacionais e mercado interno: uma comparação entre as análises de Celso Furtado e as prescriçôes dos RDHs/PNUD/ONU}

dos habitantes do planeta. O problema é que esses diagnósticos realistas não são suficientes para a formulação de prescrições também realistas e capazes de colocar em relevo os atuais desequilíbrios de poder que dão sinais de impossibilidade de haver um crescimento econômico distributivo por reduzido que seja. De modo pouco convincente, seus elaboradores dizem: "Es necesario hacer decididos esfuerzos para evitar el crecimiento sin empleo, sin raices, sin equidad, sin voz de las comunidades $y$ sin futuro" (PNUD/RDH, 1996, p.4).

No concernente aos diagnósticos feitos pelos produtores e encampadores dos RDHs a respeito das disparidades internacionais, deve-se verificar como eles lidam com os efeitos perversos da debilidade dos países do Eixo Sul nos mercados internacionais. A dependência de exportação de produtos primários, "los cuales representan muchas veces el 90\% de las exportaciones de paises africanos y el 65\% de las de países de América Latina" (PNUD/RDH, 1992, p.23), os preços baixos de tais produtos e sua constante desvalorização, em face dos produtos que contêm tecnologias cada vez mais sofisticadas, são elementos destacados na feitura dos diagnósticos. Todavia, essas dificuldades são amenizadas e tidas como superáveis quando passam dos diagnósticos para as prescrições que visam alcançar um desenvolvimento sustentável. O que não quer dizer que as propostas sejam simplistas ou voltadas para detalhes menores da vida social, econômica e política. Veja-se o QUADRO 1.

QUADRO 1: PNUD/RDH, 1992

En términos generales, los requerimientos mínimos para lograr un desarrollo sostenible incluyen:

- La eliminación de la pobreza.

- Una reducción en el crecimiento demográfico.

- Una distribución más equitativa de los recursos.

- Personas más saludables, instruidas y capacitadas.

- Gobiernos descentralizados más participativos.

- Sistemas de comercio más equitativos y abiertos, tanto internos como externos, incluyendo aumento de la producción para consumo local.

- Mejor comprensión de la diversidad de ecosistemas, soluciones localmente adaptadas para problemas ambientales y mejor monitoreo del impacto ambiental producido por las actividades de desarrollo".

Fonte: PNUD/RDH, 1992, p.48.

Em meio às prescrições, nota-se o quanto tem vida longa, no interior dos órgãos componentes do sistema das Nações Unidas, uma proposta, a de que o desenvolvimento sustentável depende da redução das taxas de nascimento, tem 
gerado muitos embates políticos entre seus técnicos graduados. Este tipo de prescrição já estava presente no seio da Organização das Nações Unidas (ONU) desde a década de 1950. Josué de Castro, presidente da Organização das Nações Unidas para Alimentação e Agricultura (FAO), travou uma verdadeira batalha contra o que ele denominava postura malthusiana ${ }^{5}$ de ligar o desenvolvimento ao controle das taxas de natalidade.

Não obstante todas as metas postas no quadro acima terem a mesma importância, não será possível discutir todas elas neste artigo, o qual está mais atento à meta de geração de um "sistemas de comercio más equitativos y abiertos, tanto internos como externos, incluyendo aumento de la producción para consumo local" (PNUD/RDH, 1992, p.48). Como é possível ler essas metas à luz das discussões de Celso Furtado? Quais são as implicações desse tipo de proposta? Em primeiro lugar, tal proposta parece sugerir soluções fortemente ancoradas nas relações externas. As estratégias de valorização de soluções pautadas na expansão do mercado interno parecem subalternizadas às relações vindas de fora e comandadas de fora para dentro: "Por mais importante que seja a inserção internacional, esta não é suficiente para dinamizar o sistema econômico. Num mundo dominado por empresas transnacionais, esses sistemas heterogêneos somente sobrevivem e crescem por vontade política apoiada em um projeto com raízes históricas". (FURTADO, 1992a, p.5).

O elemento mais relevante seria, então, "a opção política orientada para formar uma sociedade apta a assumir um papel dinâmico neste processo" (FURTADO, 2004b, p.4), o que exigiria muito mais do que "establecer un equilibrio correcto, más eficiente y efectivo, entre disminuir las disparidades internas y mantenerse al tanto del progreso y el desarrollo internacionales" (PNUD/RDH, 1992, p.100).

Celso Furtado chama atenção para duas questões: os desequilíbrios de poder provocados pelo modo como se organizam os parâmetros que regem a economia internacional e a necessidade de considerar as condições históricas a fim de elaborar qualquer prescrição para ampliar as chances de um desenvolvimento social sustentável e equitativamente inclusivo. Essas duas questões são pouco exploradas pela abordagem prospectiva dos relatórios. Em alguns momentos, observa-se, até mesmo, a formulação de estratégias para evitá-las. Com efeito, para Chang (2004, p. 215) [a] "maioria das instituições atualmente recomendadas aos países em desenvolvimento como parte do pacote de 'boa governança' foram, na verdade, resultados, e não causas, do desenvolvimento econômico dos PADs [países atualmente desenvolvidos]".

À luz dos últimos escritos de Celso Furtado pode-se dizer que os elaboradores dos RDHs falham ao sugerir políticas de desenvolvimento humano pouco atreladas

\footnotetext{
5 Referente às teorias de Thomas Malthus (1766-1834) sobre controle populacional.
} 


\section{Disparidades internacionais e mercado interno: uma comparaçáo entre as análises de Celso Furtado e as prescriçôes dos RDHs/PNUD/ONU}

e não-condicionadas a uma maior dinamicidade do mercado interno. Fracassam também, ao não enfrentar o dilema que atinge uma parte expressiva dos países do Eixo Sul: a baixa capacidade "de poupança pública e privada" e a falta de "maior disciplina e transparência no uso das divisas geradas pelas exportações" (FURTADO, 1992a, p.6).

Em entrevista concedida a Eduardo Pereira Nunes, publicada em 2003, Furtado (2003a, p. 16) reconecta tais problemas às suas reflexões teóricas sobre o subdesenvolvimento. Este, diz ele, "cria um sistema de distribuição de renda perverso, que sacrifica os grupos de renda baixa". Não é possível, nos limites deste artigo, retomar as densas discussões sobre a teoria do subdesenvolvimento, mas Furtado indica os caminhos para a orientação do debate. "A elevação dos salários é o que há de mais difícil num país como o Brasil. Isso é uma deformação social, que no fundo é o espelho do subdesenvolvimento" (FURTADO, 2003a, p. 17). O desafio que o autor coloca - em relação aos quais os autores dos RDHs parecem ser mais reticentes - diz respeito às dificuldades de enfrentar tanto os poderes globais que, em grande medida, definem os parâmetros e os modelos de desenvolvimento quanto, simultaneamente, as disparidades sociais internas. "O poder está se concentrando em todos os planos e isso vai criar dificuldades novas. Evidentemente, o que esperamos é que países como o Brasil se unam para lutar por novas formas de desenvolvimento" (FURTADO, 2003a, p.17).

O subdesenvolvimento, dessa perspectiva, é realmente um fenômeno de alta complexidade. Na medida em que se concentra renda, cria-se um segmento minoritário de alto padrão de consumo com acesso a um mercado privilegiado, mas com baixo impacto no processo produtivo nacional. Portanto, alega Furtado (2003a, p. 19), "o mercado interno é que tem de se transformar em mercado de massa. [...] É uma luta que integra, por um lado, a questão de privilegiar o mercado interno e, por outro, a de privilegiar a desconcentração da renda".

Os escritos de Celso Furtado (1992a, p.6) registram que prescrições de desenvolvimento que não enfrentam nem o problema da "eficácia [ou não] dos instrumentos de comando macroeconômico" nem os desafios inerentes à necessidade de sanear as "finanças públicas" e de disciplinar "os fluxos monetários e financeiros" tendem a não atingir o âmago dos problemas antepostos ao desenvolvimento, caso este traga em seu bojo "um projeto social subjacente" (FURTADO, 2004b, p.3). Esse modo de entender o desenvolvimento como intrincado jogo, em múltiplos níveis, entre muitas configurações (Estados, governos, organismos internacionais, empresas, sindicatos, associações de interesses diversos, entre várias outras organizações da sociedade civil) encontra-se exposto da seguinte forma por Norbert Elias (1999c):

Quando somos confrontados com os problemas dos 'países em vias de desenvolvimento' varrem-se os obstáculos à compreensão de que as sociedades são 
configurações de pessoas interdependentes. Ao procurar o desenvolvimento destas sociedades, tentando aliviar a pobreza de todo o povo e não só a de alguns dos seus membros, são necessárias medidas decisivas para regular a produtividade e o rendimento de todos os indivíduos politicamente integrados num Estado particular. (ELIAS, 1999c, p. 160)

Os produtores e encampadores do RDH de 1996 afirmavam que, para haver um projeto social subjacente, era necessária uma mudança de paradigma. Ou seja, o desenvolvimento não poderia ser pensado somente como resultado do crescimento econômico. Argumentavam que esses câmbios de conhecimentos, saberes e práticas estariam sendo impulsionados, desde 1990, pelas proposições presentes nos RDHs. Eles dizem: "para que el avance del desarrollo sea valioso y legítimo - a escala tanto nacional como internacional - es preciso que se centre en el ser humano, que esté distribuido en forma equitativa y que sea sostenible social y ecológicamente" (PNUD/RDH, 1996, p.3).

Este tipo de afirmação, o de que é somente a partir de 1990, quando se iniciam as publicações dos RDHs, que brota uma preocupação em associar crescimento econômico e desenvolvimento social e sustentável, é a prova mais evidente de que os feitores dos RDHs se refugiam, para usar uma terminologia posta por Norbert Elias (1998), no presente para justificar as suas idealizações. Desde meados do século XX está em curso um processo de formulação de conhecimentos que vem atestando que o desenvolvimento é a busca de "vias e processos de aumentar o rendimento da maioria e não o aumento da riqueza de um grupo de pessoas" (ELIAS, 1999, p.159).

Os conhecimentos, saberes e práticas políticas de Celso Furtado se mostraram, desde a década de 1950, preocupados com o desenvolvimento social; basta observar seus textos A fantasia organizada (1997a) e A fantasia desfeita (1997b) em que ele narrava seu empenho à frente de políticas ${ }^{6}$ que tentavam gerar outro padrão de organização social e que antecederam, em muitos anos os RDHs ${ }^{7}$. Era uma luta para retirar as travas sociais, políticas e econômicas, a fim de fomentar-se um desenvolvimento social e sustentável. Dizer que a possível transição para um paradigma de associação entre crescimento econômico e desenvolvimento social e humano só ocorreu com a criação dos RDHs é desconsiderar um processo histórico anterior formador de saberes, conhecimentos e práticas. Os elaboradores do RDH

\footnotetext{
6 Celso Furtado foi técnico da Comissão Econômica para a América Latina (CEPAL). Esteve à frente da Operação Nordeste e da Superintendência para o Desenvolvimento do Nordeste (SUDENE). Foi ainda ministro do planejamento no governo de João Goulart.

7 Há algo que salta aos olhos no RDH de 1996 que trata da associação entre crescimento econômico e desenvolvimento: a não-menção, na bibliografia, de qualquer escrito de Celso Furtado. Aparece menção a Paul Streeten do Hemisfério Norte e muitos outros, mas não ao pensador brasileiro.
} 


\section{Disparidades internacionais e mercado interno: uma comparação entre as análises de Celso Furtado e as prescriçôes dos RDHs/PNUD/ONU}

de 1996 fazem afirmações que se inscrevem nos debates postos ao longo da segunda metade do século XX.

No hay vínculos automáticos entre crecimiento económico y desarrollo humano, pero cuando se forjan tales vínculos mediante políticas deliberadas, puede lograrse un refuerzo mutuo, de modo que el crecimiento económico impulse eficaz y rápidamente el desarrollo humano. Las políticas gubernamentales tienen importancia vital (PNUD/RDH, 1996, p.III).

O que está posto nessa passagem foi matéria de amplos embates políticos ao longo das décadas de 1950,1960, 1970 e 1980. Não é possível desconsiderar todo um processo de formação de conhecimentos que desaguaram nas proposições contidas nos documentos do PNUD intitulados RDHs globais, regionais e nacionais. Não se está desprezando o fato de que os relatórios estão, conforme afirmam os sociólogos chilenos Cláudio Zincke e Elaine Gonzáles (2006), produzindo conhecimento e até mesmo formatando um campo epistêmico. Questiona-se sim a maneira como, em algumas situações, se tenta fazer parecer que o conhecimento não é cumulativo, mas pautado numa quebra de paradigma que estaria reinventando, integralmente, a noção de desenvolvimento. Como afirma Norbert Elias (1998), nenhum movimento de ideias, relacionado ao processo de conhecimento, é inteiramente um começo. Todo movimento está sempre inscrito numa longa cadeia de saberes e práticas.

\section{Considerações finais}

Tanto Celso Furtado quanto os elaboradores dos RDHs de 1992, 1994 e 1996 preocupam-se, cada um a seu modo, com as disparidades sociais, políticas e econômicas. Suas análises não situam o debate acerca das disparidades somente no âmbito dos mercados internacionais e das relações de cooperação externas. A tematização das disparidades ganha um papel central tanto no primeiro quanto nos segundos. Todavia, é necessário assinalar que o modo como eles (Celso Furtado e os produtores dos RDHs) encaram tais relações díspares guardam poucas semelhanças e muitas discrepâncias. Quanto às semelhanças pode-se dizer que elas estão no tratamento das disparidades sociais, econômicas e políticas em escalas que vão do âmbito internacional para o âmbito nacional e vice-versa.

Nos seus diversos materiais divulgados nas décadas de 1990 e 2000, Furtado assinala como são díspares as possibilidades de cada país encontrar lugar nos mercados, implantar processos econômicos de industrialização em tempos de globalização e aumentar a participação dos indivíduos na renda nacional. De um 
modo ou de outro, essas disparidades são também ressaltadas nos relatórios, mas há diferenças significativas no que diz respeito ao modo delas serem trazidas para o campo da discussão política.

A diferença está muito mais no modo como Furtado (2004b, p.4) concebe as possibilidades de ir vencendo as disparidades através da abertura de "caminho[s] de acesso a formas sociais mais aptas a estimular a criatividade humana e responder às aspirações da coletividade". Ao falar em liberar a energia humana, Furtado (1992, p.75) está, de certa maneira, fazendo críticas ao "trabalho de engenharia social em que tudo está previamente estabelecido".

Ainda que os formuladores dos RDHs defendam a participação política, a democratização do acesso a serviços sociais, à renda, a terras e a programas, que tornem viável a sobrevivência dos mais pobres em suas pequenas propriedades, a inserção das mulheres agricultoras, como beneficiárias dos processos de reforma agrária (PNUD/RDH, 1996), a abordagem prospectiva dos relatórios se enquadra, muito mais, como propulsora de ações, práticas e procedimentos de engenharia social em que vão se desenvolvendo e expandindo, por parte do Estado, dos governantes, dos organismos internacionais, formas de escoltar e controlar as mudanças. Pode-se dizer: mas a sociedade civil organizada tem um papel importante nesse processo. Sem dúvida, e os produtores dos relatórios insistem muito nisso, mas o caráter difuso e pouco claro não permite saber quais seriam as possibilidades de que a sociedade civil atuasse, de fato, balizando as ações de outros agentes, e deixam, então, sempre a sensação de um processo de controle até mesmo sobre os vários segmentos da sociedade civil.

\section{INTERNATIONAL DISPARITIES AND INTERNAL MARKET: A COMPARISON BETWEEN CELSO FURTADO'S PERSPECTIVES AND THE PRESCRIPTIONS OF THE HUMAN DEVELOPMENT REPORTS}

ABSTRACT: Celso Furtado's analysis shows what are the obstacles that impede, in each socio-historical context, the human development in Latin America in general and specifically in Brazil. Therefore, this research adopts a qualitative methodological perspective, through a bibliographical and documentary analysis whose objective is to unveil the political meanings of prospective approaches analyzed in this article (the one built in the UNDP / UN Human Development Reports and the one elaborated by Celso Furtado). It should be noted that the main difference between these two ways of dealing with development lies in the way each of them deals with the socio-historical process in relation to the blockages that intervene in the construction of a valuing future of human improvements.

KEYWORDS: Social and human development. Future. Prospective approaches. 
Disparidades internacionais e mercado interno: uma comparação entre as análises de Celso Furtado e as prescriçôes dos RDHs/PNUD/ONU

\section{DISPARIDADES INTERNACIONALES Y MERCADO INTERNO: UNA COMPARACIÓN ENTRE LOS ANÁLISIS DE CELSO FURTADO Y LAS PRESCRIPCIONES DE LOS RDHS / PNUD / ONU}

RESUMEN: Los análisis de Celso Furtado demostraron cuáles eran las trabas que impiden, en cada contexto socio-histórico, el desarrollo social y humano en América Latina en general, y en Brasil particularmente. Esta investigación adopta, entonces, una perspectiva metodológica cualitativa realizada por medio de un análisis bibliográfico y documental, cuyo objetivo es desentrañar los sentidos y significados políticos de los enfoques prospectivos de Celso Furtado y de los elaboradores de los Informes del Desarrollo Humano analizados en este artículo. Cabe destacar que la diferencia central entre esas dos formas de tratar el desarrollo, está en el modo en como cada una de ellas se ocupa del proceso socio histórico en lo concerniente a los bloqueos que se interponen en la construcción de un devenir valorizador de las mejoras humanas.

PALABRAS CLAVE: Desarrollo social y humano. Devenir. Enfoques prospectivos.

\section{REFERÊNCIAS}

AGARWALA, Amar Narain. e SINGH, Sampat. Pal. (Orgs) A economia do desenvolvimento. São Paulo: Contraponto, Fundação Celso Furtado, 2010.

BRANDÃO, Carlos. Celso Furtado: subdesenvolvimento, dependência, cultura e criatividade. Revista de Economia Política de las Tecnologias de la Información y de la Comunicación. São Cristovão/SE, vol.XIV, jan-abr 2012.

CEPAL - Comissão Econômica para a América Latina. El desarrollo social de América latina en la postguerra. Buenos Aires: Solar/Hachette, 1963.

CHANG, Ha-Joon. Chutando a Escada: a estratégia do desenvolvimento em perspectiva histórica. São Paulo: Ed. Unesp, 2004.

CÊPEDA, Vera, A. Celso Furtado e a interpretação do subdesenvolvimento. Perspectivas, São Paulo, n. 28, p. 57-77, 2005. Disponível em: <http://seer.fclar.unesp.br/perspectivas/ article/view/11>. Acessado em: 10 ago. 2017.

. Entre a economia e a política os conceitos de periferia e desenvolvimento em Celso Furtado. Sinais Sociais, v 7, n 19, p.88-119, mai/ago. 2012. Disponível em: <http:// pesquisa.bvsalud.org/bvsvs/resource/pt/bps-1743>. Acessado em 25 nov. 2018. 
ELIAS, Norbert. Envolvimento e alienação. Rio de Janeiro: Bertrand Brasil, 1998.

A evolução do conceito de desenvolvimento. In: . Introdução à Sociologia. Lisboa: Edições 70, 1999. p.159-167.

. O modelo de jogos. In: . Introdução à Sociologia. Lisboa: Edições 70, 1999a. p.77-112. . Introdução. In: Introdução à Sociologia. Lisboa: Edições 70, 1999 b. p. 13-34.

FUKUDA-PARR, Sakiko. Operacionalizando as ideias de Amartya Sen sobre capacidades, desenvolvimento, liberdade e direitos humanos - o deslocamento do foco das políticas de abordagem do desenvolvimento humano. 2002. Disponível em: <www.soo. sdr.sc.gov.br/index.php?option=com_docman...70>. Acessado em: 11 ago. 2017.

FURTADO, Celso. Desenvolvimento e subdesenvolvimento. Rio de Janeiro: Fundo de Cultura, 1961.

. Dialética do desenvolvimento. Rio de Janeiro: Fundo de Cultura, 1964.

. Pressupostos da política cultural. In: D'AGUIAR, Rosa F. (org). Ensaios sobre cultura e o Ministério da Cultura. Rio de Janeiro: Contraponto; Centro Internacional Celso Furtado, 2012 [1986].

. O mito do desenvolvimento econômico. Rio de Janeiro: Paz e Terra, 1974

. Criatividade e dependência na civilização industrial. Rio de Janeiro: Paz e Terra, 1978.

. Estado e empresas transnacionais na industrialização periférica. Revista de Economia Política, São Paulo, v.1, n.1. p.41-49, 1981.

. Brasil: a construção interrompida. Rio de Janeiro: Paz e Terra, 1992.

. Globalização das estruturas econômicas e identidade nacional. Estudos Avançados, São Paulo, IEA-USP, v.6, n.16, p.55-64,1992a.

. A invenção do subdesenvolvimento. Revista de Economia Política, São Paulo, vol. 15, n. 2 (58), pp. 5-9, abril-junho 1995.

. Ares do mundo. In: Obra autobiográfica. Rio de Janeiro: Paz e Terra, 1997. p 41-101. Tomo III.

. A fantasia organizada. In: Obra autobiográfica. São Paulo: Paz e Terra, 1997a. p. 87-359. Tomo I. 


\section{Disparidades internacionais e mercado interno: uma comparação entre as análises de Celso Furtado e as prescriçôes dos RDHs/PNUD/ONU}

. A fantasia desfeita. In: Obra autobiográfica. São Paulo: Paz e Terra, 1997b. p. 27-306, Tomo II.

. Seca e poder: entrevista com Celso Furtado. São Paulo: Fundação Perseu Abramo, 1998.

. O capitalismo global. Rio de Janeiro: Paz e Terra, 1998a.

. O longo amanhecer. São Paulo: Paz e Terra, 1999.

. A reconstrução do Brasil. Praga: estudos marxistas, São Paulo: Hucitec, n.8, p.9-13, ago. 1999a.

. Reflexões sobre a crise brasileira. Revista de Economia Política. São Paulo, v.20, n.4 (80), pp.3-7, dez. 2000. Disponível em: <www.centrocelsofurtado.org.br>. Acessado em: 20 jul. 2017.

. Em busca de novo modelo. Rio de Janeiro: Paz e Terra. 2002.

. Entrevista. Rio de Janeiro: Eduerj, 2002a.

. Entrevista: A atual situação mundial. 2003. Disponível em: <www.centro celsofurtado.org.br>. Acessado em: 20 jul. 2017.

O Brasil do século XXI. In IBGE. Estatísticas do século XX. Rio de Janeiro, IBGE, 2003a. pp. 11-24. Disponível em: <www.centrocelsofurtado.org.br $>$. Acessado em: 20 jul. 2017.

. Receita para o crescimento. Jornal da Unicamp, Campinas, p.3, 27 setembro a 03 de outubro de 2004. Disponível em: <www.centrocelsofurtado.org.br $>$. Acessado em: 20 jul. 2017.

. Nordeste foi o mais prejudicado em 1964. O Estado de S. Paulo, 04 abr.2004a. Caderno A, p. 9. Disponível em: <www.centrocelsofurtado.org.br>. Acessado em 20 jul. 2017

. Os desafios da nova geração. Jornal dos Economistas. São Paulo, 4 Jun. 2004b, p.3. Disponível em: <www.centrocelsofurtado.org.br>. Acessado em: 20 jul. 2017.

GOLDTHORPE, J. E. Sociologia do terceiro mundo: disparidade e envolvimento. Rio de Janeiro: Zahar, 1977.

HIRSCHMAN, Albert. Confissão de um dissidente: revisitando a estratégia do desenvolvimento econômico. In: . A economia como ciência moral e política. São Paulo: Brasiliense, 1986. 
PINTO, Aníbal. Distribuição de renda na América Latina e desenvolvimento. Rio de Janeiro: Zahar, 1976.

PREBISCH, Raúl. Dinâmica do desenvolvimento Latino-americano. Rio de Janeiro: Fundo de Cultura, 1964.

. Cinco etapas em mi pensamiento sobre el desarrollo. In MEIER, G.M. e SEERS, D. (org.) Pioneros del desarrollo. Madrid: Tecnos, 1986. P.178.

A crise do desenvolvimento argentino. São Paulo: Vértice, 1987.

PNUD/RDH (1992). Relatório do Desenvolvimento Humano: Uma nova visão sobre o desenvolvimento humano internacional. PNUD/ONU. 1992. Disponível em: $<$ http://hdr. undp.org/en/reports/global/hdr1991>. Acessado em: 03 mar. 2017

PNUD/RDH (1994). Relatório do Desenvolvimento Humano: Um programa para a cúpula mundial sobre desenvolvimento humano. Disponível em: Disponível em: $<$ http://hdr.undp. org/en/reports/global/hdr1994>. Acessado em: 20 jan. 2017.

PNUD/RDH (1996). Relatório do Desenvolvimento Humano: Crecimiento económico para propriar el desarrollo humano? PNUD/ONU. 1996. Disponível em: $<\mathrm{http}: / /$ hdr.undp. org/en/reports/global/hdr1996>. Acessado em: 02 fev. 2017.

PNUD/RDH (1998). Relatório do Desenvolvimento Humano: Mudar as pautas atuais de consumo para o desenvolvimento humano do futuro. PNUD/ONU. 1998. Disponível em: $<$ http://hdr.undp.org/en/reports/global/hdr1998>. Acessado em: 02 jul. 2018.

PNUD/RDH (1999). Relatório do Desenvolvimento Humano: A mundialização com rosto humano. PNUD/ONU. 1999. Disponível em: $<$ http://hdr.undp.org/en/reports/global/ hdr1999>. Acessado em: 22 jul. 2017.

PNUD/RDH (2001). Relatório de Desenvolvimento Humano 2001: Fazendo as novas tecnologias trabalhar para o desenvolvimento humano. Disponível em: $<$ http://www.pnud. org/en/reports/global/hdr2001/download/pt>. Acessado em: 11 jan. 2017.

PNUD/RDH (2003). Relatório do Desenvolvimento Humano/2003: Um pacto entre nações para eliminar a pobreza humana. Disponível em $<$ http://www.pnud.org/en/reports/global/ hdr2003/download/pt >. Acessado em: 11 fev. 2017.

STREETEN, Paul. Fronteras de los estudios sobre el desarrollo. México: Fondo de Cultura Económica, 1982.

SEN, Amartya. Desenvolvimento como liberdade. São Paulo: Cia das Letras, 2005. . A ideia de justiça. São Paulo: Cia das Letras, 2011. 
Disparidades internacionais e mercado interno: uma comparação entre as análises de Celso Furtado e as prescriçôes dos RDHs/PNUD/ONU

TOLIPAN, Ricardo; TINELI, Arthur. A controvérsia sobre distribuição de renda e desenvolvimento. Rio de Janeiro: Zahar, 1975.

UL HAQ, Mahbub. Reflections on Human Development. Nova York: Oxford University Press, 1995. 288p.

WOORTMANN, Klaas Axel. Modernização e desenvolvimento. Textos: Série Antropologia, n.120. Brasília, 1991. Disponível em: http://dan.unb.br/dan-producaocientifica/serie antropologia/lista/77-serie-antropologia-pag-07-101-150 Acessado em: 10 jul.2017.

ZINCKE, Cláudio R.; GONZÁLES, Elaine A. El impacto de los informes de desarrollo humano del PNUD en Chile. Santiago de Chile, Universidad Alberto Hurtado, Departamento de Sociologia, Julio 2006. Disponível em: <www.sociologia.uahurtado.cl $>$. Acessado em: 10 jun. 2017.

Recebido em 14/12/2017.

Aprovado em 14/10/2018. 
